\title{
PENGARUH PERUBAHAN PENGHASILAN TIDAK KENA PAJAK (PTKP) TERHADAP PENERIMAAN PAJAK PENGHASILAN ORANG PRIBADI PADA KANTOR PELAYANAN PAJAK PRATAMA ARGAMAKMUR
}

\author{
Yun Fitriano', Febri Dwi Rimbawati $^{2}$ \\ ${ }^{1 \& 2}$ Universitas Dehasen Bengkulu \\ vun.fitriano@gmail.com ${ }^{1}$, febridwirimbawati@gmail.com ${ }^{2}$
}

\begin{abstract}
The purpose of this study is to determine the influence of Non-Taxable Income (PTKP) on Personal Income Tax Acceptance at Kantor Pelayanan Pajak Pratama Argamakmur. PTKP is a certain amount of income that is not taxable which can reduce the amount of personal income tax revenue. The method used in this research is to use data collection method of documentation and analysis method used is descriptive quantitative. The analysis in this study uses a simple linear regression formula and coefficient of determination with the help of SPSS application. And to prove the effect of Non-Taxable Income (PTKP) on Personal Income Tax Acceptance then used hypothesis test ( $t$ test). The results of the simple linear regression data data of $Y=9461924484.969-1054.200(X)$ and data analysis using the determination coefficient is 0.106 with the contribution of the variable non-taxable income $(X)$ to the receipt of personal income tax is $10.6 \%$, while the rest is influenced by other variables not examined in this study. From the results of the data processing, the value of t-count is -2,010 and the value of $t$ table is 1.305. if the two values are compared, then the tcount is $-2.010 \leq t$ table 1.305 which means that the Non-Taxable Income has a significant negative effect on the Personal Income Tax Revenue.
\end{abstract}

Keywords: non-taxable income, personal income tax revenue

\section{PENDAHULUAN}

Pajak merupakan pembayaran yang diwajibkan kepada setiap warga negara yang kontraprestasinya tidak bersifat langsung. Penerimaan pajak bagi suatu negara merupakan suatu pos penerimaan yang penting. Pada banyak negara penerimaan pajak merupakan penerimaan yang paling utama dengan porsi yang paling besar dalam membiayai pengeluaran yang dilakukan pemerintah. Indonesia sebagai negara berkembang memiliki ketergantungan yang kuat terhadap penerimaan dari pajak. dimana pajak menyumbang rata-rata lebih dari $85 \%$ dari keseluruhan pendapatan negara dalam berbagai fungsi kenegaraan. Indonesia merupakan suatu negara yang menerapkan tarif pajak yang variatif kepada masyarakatnya, yaitu sesuai dengan tingkatan golongan pendapatannya. Pajak adalah salah satu penerimaan Negara yang berpotensi besar dalam membiayai pengeluaran serta biaya negara yang dibebankan kepada masyarakat. Salah satu pajak yang di bebankan oleh pemerintah kepada masyarakatnya adalah Pajak Penghasilan $(\mathrm{PPh})$. Pajak Penghasilan (PPh) adalah pajak yang terutang atas penghasilan yang 
menjadi kewajiban bagi wajib pajak orang pribadi atau badan atas penerimaan yang berupa gaji/upah, honorarium, tunjangan dan pembayaran lainnya sesuai dengan peraturan yang telah ditetapkan oleh pemerintah. Pajak penghasilan merupakan pajak subjektif yang dalam pengenaannya harus memperhatikan keadaan pribadi subjek pajak. Hal ini diwujudkan dengan pemberian kelonggaran berupa Penghasilan Tidak Kena Pajak (salim \& Syafitri, 2013:1).

Penghasilan Tidak Kena Pajak (PTKP) adalah batas biaya hidup minimum yang wajib dipenuhi oleh seseorang untuk dapat hidup dengan layak, sehingga tidak dapat diganggu gugat oleh siapapun. PTKP adalah komponen pengurang dalam penghitungan $\mathrm{PPh}$ pasal 21, yaitu sebagai komponen pengurang dalam pemotongan penghasilan yang dapat dikenakan tarif pajak yang terutang. Semakin besar batas PTKP akan semakin kecil pajak terutang yang disetor oleh wajib pajak orang pribadi atau badan. Perubahan PTKP disesuaikan dengan keadaan ekonomi di Indonesia. Menururt Darwis (2012) perubahan PTKP ini merupakan strategi dari pemerintah untuk menekan tingkat inflasi yang terus merangkak naik dan untuk memberikan stimulus konsumsi domestik sehingga dapat meningkatkan pertumbuhan ekonomi.

Menurut Darwis (2012) setidaknya terdapat tiga dampak positif setelah nilai PTKP dinaikkan. Hal pertama adalah meningkatnya konsumsi dalam negeri, dengan adanya kenaikan nilai PTKP maka daya beli masyarakat akan meningkat, karena biasanya penghasilan yang didapat dipotong untuk membayar pajak, sekarang bisa mengalokasikannya untuk dikonsumsi atau dibelanjakan. Hal kedua adalah meningkatnya tabungan atau saving masyarakat, uang yang sebelumnya dibayarkan pajak, sekarang bisa dialokasikan untuk ditabung bila tidak dibelanjakan. Ketiga, memberikan perlindungan dan keringanan bagi masyarakat yang berpenghasilan rendah seperti buruh yang berpenghasilan dibawah Rp2.000.000, agar tidak terbebani lagi dengan harus membayar pajak.

Penghasilan Tidak Kena Pajak (PTKP) sedemikian kali diubah berdasarkan Undang-Undang dan Peraturan Menteri Keuangan RI dan yang terakhir kali diatur dalam Peraturan Menteri Keuangan RI nomor 101/PMK.010/2016 , sebesar Rp.54.000.000,00 untuk diri Wajib Pajak, Rp. 4.500.000,00 untuk Wajib Pajak kawin, Rp. 54.000.000,00 untuk penghasilan istri yang digabungkan, Rp. 4.500.000,00 untuk tambahan anggota keluarga sedarah dan semenda dalam satu garis keturunan lurus serta anak angkat yang menjadi tanggungan sepenuhnya. Jadi, PTKP dapat dikatakan sebagai keringanan yang diberikan oleh pemerintah kepada penduduk berpenghasilan rendah (redistribusi pendapatan). Namun keringanan ini (kebijakan penaikan PTKP) harus dipertimbangkan dengan baik, karena menopang kehidupan masyarakat khususnya kelas menengah kebawah.

\section{TINJAUAN PUSTAKA}

\section{Pajak}

Menurut Undang-Undang No. 28 Tahun 2007 tentang Perubahan Ketiga Atas Undang-Undang No. 6 Tahun 1983 Tentang Ketentuan Umum dan Tata 
Perpajakan, mendefinisikan pajak sebagai berikut : "Pajak adalah kontribusi wajib kepada negara yang terutang oleh orang pribadi atau badan yang bersifat memaksa berdasarkan Undang-Undang, dengan tidak mendapatkan imbalan secara langsung dan digunakan untuk keperluan negara bagi sebesar-besarnya kemakmuran rakyat."

\section{Wajib Pajak}

Wajib pajak adalah orang pribadi atau badan, meliputi pembayaran pajak, pemotongan pajak, dan pemungut pajak yang mempunyai hak dan kewajiban perpajakan sesuai dengan ketentuan peraturan perundang-undangan yang berlaku.

\section{Pajak Penghasilan}

Menurut Priantara (2016:173) "Pajak Penghasilan adalah pajak yang dikelola oleh Pemerintah Pusat dan memberikan kontribusi signifikan kepada penerimaan Negara. PPh merupakan pajak langsung karena beban pajak ini langsung dipikul oleh penerima atau pemilik penghasilan."

\section{Penghasilan Tidak Kena Pajak (PTKP)}

Menurut Resmi (2013:96) Penghasilan Tidak Kena Pajak (PTKP) merupakan jumlah penghasilan tertentu yang tidak kena pajak. untuk menghitung besarnya Penghasilan Kena Pajak Wajib Pajak orang pribadi dalam negeri, penghasilan netonya dikurangi dengan jumlah Penghasilan Tidak Kena Pajak. Manfaat yang dapat diperoleh bagi wajib pajak orang pribadi antara lain:

a. Mengurangi pajak yang harus dibayar WPOP

b. Memberikan lebih banyak penghasilan dapat dibawa pulang kepada WPOP;

c. Mengurangi biaya hidup, dikarenakan setiap ada tanggungan berupa kawin atau menikah, memiliki anak dan tanggungan karena hubungan keluarga bertambah maka PTKP akan bertambah dengan maksimal 3 tanggungan.

Perubahan PTKP dari tahun 2012 sampai dengan 2016 beserta peraturan, dijelaskan dalam tabel dibawah ini:

\begin{tabular}{|l|l|l|}
\hline \multicolumn{1}{|c|}{ Peraturan } & \multicolumn{1}{|c|}{ Jumlah (Rp) } & \multicolumn{1}{c|}{ Uraian } \\
\hline $\begin{array}{l}\text { Undang-undang nomor } \\
\text { Rp15.840.000,00 } 2008\end{array}$ & Rp 1.320.000,00 & Wajib Pajak orang pribadi \\
Wajib Pajak yang kawin \\
Rp 15.840.000,00 $1.320 .000,00$ & $\begin{array}{l}\text { Seorang isteri yang } \\
\text { penghasilannya digabung } \\
\text { dengan penghasilan suami } \\
\text { Setiap anggota keluarga sedarah } \\
\text { dan keluarga semenda dalam } \\
\text { garis keturunan lurus serta anak } \\
\text { angkat, yang menjadi } \\
\text { tanggungan sepenuhnya, paling } \\
\text { banyak 3 (tiga) orang untuk } \\
\text { setiap keluarga. }\end{array}$ \\
\hline
\end{tabular}




\begin{tabular}{|c|c|c|}
\hline Peraturan & Jumlah (Rp) & Uraian \\
\hline $\begin{array}{l}\text { Peraturan Menteri } \\
\text { Keuangan RI Nomor } \\
\text { 162/pmk.011/tahun } \\
2012\end{array}$ & $\begin{array}{l}\operatorname{Rp} 24.300 .000,00 \\
\operatorname{Rp} 2.025 .000,00 \\
\operatorname{Rp} 24.300 .000,00\end{array}$ & $\begin{array}{l}\text { Wajib Pajak orang pribadi } \\
\text { Wajib Pajak yang kawin } \\
\text { Seorang isteri yang } \\
\text { penghasilannya digabung } \\
\text { dengan penghasilan suami } \\
\text { Setiap anggota keluarga sedarah } \\
\text { dan keluarga semenda dalam } \\
\text { garis keturunan lurus serta anak } \\
\text { angkat, yang menjadi } \\
\text { tanggungan sepenuhnya, paling } \\
\text { banyak } 3 \text { (tiga) orang untuk } \\
\text { setiap keluarga }\end{array}$ \\
\hline $\begin{array}{l}\text { Peraturan Menteri } \\
\text { Keuangan RI Nomor } \\
\text { 122/pmk.010/tahun } \\
2015\end{array}$ & $\begin{array}{l}\operatorname{Rp} 36.000 .000,00 \\
\operatorname{Rp} 3.000 .000,00 \\
\operatorname{Rp} 36.000 .000,00\end{array}$ & $\begin{array}{l}\text { Wajib Pajak orang pribadi } \\
\text { Wajib Pajak yang kawin } \\
\text { Seorang isteri yang } \\
\text { penghasilannya digabung } \\
\text { dengan penghasilan suami } \\
\text { Setiap anggota keluarga sedarah } \\
\text { dan keluarga semenda dalam } \\
\text { garis keturunan lurus serta anak } \\
\text { angkat, yang menjadi } \\
\text { tanggungan sepenuhnya, paling } \\
\text { banyak } 3 \text { (tiga) orang untuk } \\
\text { setiap keluarga }\end{array}$ \\
\hline $\begin{array}{l}\text { Peraturan Menteri } \\
\text { Keuangan RI Nomor } \\
\text { 101/pmk.010/tahun } \\
2016\end{array}$ & $\begin{array}{l}\text { Rp 54.000.000,00 } \\
\operatorname{Rp} 4.500 .000,00 \\
\operatorname{Rp} 54.000 .000,00 \\
\operatorname{Rp} 4.500 .000,00\end{array}$ & $\begin{array}{l}\text { Wajib Pajak orang pribadi } \\
\text { Wajib Pajak yang kawin } \\
\text { Seorang isteri yang } \\
\text { penghasilannya digabung } \\
\text { dengan penghasilan suami } \\
\text { Setiap anggota keluarga sedarah } \\
\text { dan keluarga semenda dalam } \\
\text { garis keturunan lurus serta anak } \\
\text { angkat, yang menjadi } \\
\text { tanggungan sepenuhnya, paling } \\
\text { banyak } 3 \text { (tiga) orang untuk } \\
\text { setiap keluarga }\end{array}$ \\
\hline
\end{tabular}




\section{Pajak Penghasilan Orang Pribadi}

Undang undang no 36 tahun 2008 Pajak Penghasilan Orang Pribadi adalah pajak yang dikenakan terhadap subjek pajak oang pribadi atas penghasilan orang pribadi yang diterima atau diperolehnya dalam tahun pajak atau dapat pula dikenakan pajak untuk penghasilan dalam bagian tahun pajak apabila kewajiban pajak subjektifnya dimulai atau berakhir dalam tahun pajak. Tarif pajak berdasarkan Undang-Undang Nomor 36 tahun 2008

\begin{tabular}{|l|c|}
\hline \multicolumn{1}{|c|}{ Lapisan Penghasilan Kena Pajak } & Tarif pajak \\
\hline Sampai dengan Rp 50.000.000 & $5 \%$ \\
\hline Diatas Rp 50.000.000 s/d Rp 250.000.000 & $15 \%$ \\
\hline Diatas Rp 250.000.000 s/d Rp 500.000.000 & $25 \%$ \\
\hline Diatas Rp 500.000.000 & $30 \%$ \\
\hline
\end{tabular}

Sumber: Priantara (2017:282)

\section{Penerimaan Pajak}

Menurut Timbul dan Imam (2012:30) penerimaan pajak adalah : "Penerimaan pajak adalah salah satu komponen penting bagi negara untuk kemandirian dan pembiayaan pembangunan". Sumber penerimaan pajak, yaitu:

1. Pajak Penghasilan (PPh)

2. Pajak Pertambahan Nilai (PPN)

3. Pajak Penjualan atas Barang Mewah (PPnBM)

4. Bea Materai

\section{Kerangka Analisis}

Gambar 1

Kerangka analisis

\begin{tabular}{|c|c|}
\hline Perubahan Penghasilan Tidak \\
Kena Pajak (PTKP) \\
(Berdasarkan UU dan peraturan \\
menteri keuangan RI) \\
$\mathrm{X}$
\end{tabular}$\quad$\begin{tabular}{c} 
Penerimaan Pajak \\
Penghasilan Orang Pribadi \\
(PPh pasal 21) \\
$\mathrm{Y}$ \\
\hline
\end{tabular}

\section{Hipotesis}

Hipotesis dalam penelitian ini adalah :

Ho : Tidak ada pengaruh perubahan Penghasilan Tidak Kena Pajak terhadap Penerimaan Pajak Penghasilan Orang Pribadi di kantor pelayanan pajak pratama Argamakmur.

$\mathrm{Ha}$ : Ada pengaruh perubahan Penghasilan Tidak Kena Pajak terhadap Penerimaan Pajak Penghasilan Orang Pribadi di kantor pelayanan pajak pratama Argamakmur. 


\section{METODE PENELITIAN \\ Jenis Penelitian}

Jenis yang digunakan dalam penelitian ini adalah deskriptif kuantitatif. Menurut Sugiyono (2012:147) "Deskriptif Kuantitatif adalah suatu metode penelitian yang meneliti suatu metode penelitian yang meneliti status kelompok manusia, suatu objek, suatu sistem pemikiran ataupun kelas manusia masa sekarang”.

\section{Definisi Operasional}

Pengertian dan batasan-batasan variabel yang digunakan dalam penelitian ini adalah:

a. Penghasilan Tidak Kena Pajak adalah tarif dasar pengurangan terhadap penghasilan bruto orang pribadi atau perseorangan sebagai wajib pajak dalam negeri dalam menghitung penghasilan kena pajak yang menjadi objek pajak penghasilan yang harus dibayar wajib pajak di Indonesia yang terdaftar di Kantor Pelayanan Pajak Pratama Argamakmur.

b. Penerimaan Pajak penghasilan orang pribadi adalah sumber penerimaan yang dapat diperoleh secara terus-menerus dan dapat dikembangkan secara optimal sesuai kebutuhan pemerintah serta kondisi masyarakat yang diperoleh dari Penghasilan kena pajak pada orang pribadi, baik yang diperoleh dari pekerjaan bebas atau dari satu pemberi kerja,dihitung dari penghasilan neto dalam negeri maupun luar negeri, yang diperoleh dirinya maupun keluarganya serta dari kegiatan usaha utamanya maupun usaha lainnya dikurangi dengan penghasilan tidak kena pajak(PTKP).

\section{Metode Pengumpulan Sampel}

Populasi dalam penelitian ini merupakan penghasilan tidak kena pajak dan penerimaan pajak penghasilan orang pribadi di Kantor Pelayanan Pajak Pratama Argamakmur. Sampel yang digunakan adalah penghasilan tidak kena pajak untuk Wajib Pajak Orang Pribadi dan Penerimaan Pajak Penghasilan Orang Pribadi 36 bulan dari tahun 2014 (Smt II) sampai dengan tahun2017 (Smt I) pada Kantor Pelayanan Pajak Pratama Argamakmur.

\section{Metode Pengumpulan Data}

Data sekunder yang digunakan dalam penelitian ini berasal dari laporan Penerimaan Pajak Penghasilan Orang Pribadi pada Kantor Pelayanan Pajak Pratama Argamakmur. Adapun metode yang digunakan dalam penelitian ini adalah:

1. Metode Dokumentasi yaitu untuk mengumpulkan data yang ada dalam dokumen instansi. Dokumen yang diberikan bagian Pengolahan Data dan Informasi (PDI) kepada penulis yaitu laporan Penerimaan Pajak Penghasilan Orang Pribadi pada Kantor Pelayanan Pajak Pratama Argamakmur.

2. Metode Kepustakaan yaitu metode pengumpulan data yang bersumber dari literatur-literatur dan buku-buku reverensi yang berkaitan dengan masalah yang diteliti. 


\section{Metode Analisis}

Metode analisis yang digunakan dalam penelitian ini yaitu metode analisis regresi linier sederhana yang dihitung dengan rumus:

$\mathbf{Y}=\mathbf{a}+\mathbf{B x}$

Keterangan:

$\mathrm{Y}=$ variabel akibat/dependen (Penerimaan Pajak Penghasilan Orang Pribadi)

$\mathrm{X}=$ variabel faktor penyebab/independen (Perubahan Penghasilan Tidak Kena Pajak)

$\mathrm{a}=$ bilangan konstan

$\mathrm{b}=$ koefisien arah regresi linear.

\section{Uji Hipotesis}

Penelitian ini menggunakan Program SPSS dan tingkat signifikansi 0,10 ( $\alpha=10 \%)$ dengan kriteria sebagai berikut

1. Jika t hitung $\geq$ dari $t$ tabel maka Ho ditolak dan Ha diterima artinya Perubahan Penghasilan Tidak Kena Pajak berpengaruh signifikan terhadap Penerimaan Pajak Penghasilan Orang Pribadi.

2. Jika $t$ hitung $\leq$ dari $t$ tabel maka Ho diterima dan menolak Ha artinya bahwa Perubahan Penghasilan Tidak Kena Pajak tidak berpengaruh terhadap Penerimaan Pajak Penghasilan Orang Pribadi

HASIL PENELITIAN DAN PEMBAHASAN

Jumlah Penerimaan Pajak Penghasilan Orang Pribadi pada Kantor Pelayanan Pajak Pratama Argamakmur

Tarif PTKP dan penerimaan pajak penghasilan orang pribadi

\begin{tabular}{|l|l|l|}
\hline \multicolumn{1}{|c|}{ Tahun } & \multicolumn{1}{|c|}{$\begin{array}{c}\text { Penghasilan } \\
\text { Tidak Kena Pajak }\end{array}$} & $\begin{array}{c}\text { Penerimaan Pajak } \\
\text { Penghasilan Orang Pribadi }\end{array}$ \\
\hline 2014 (Smt II) & 24.300 .000 & 45.557 .188 .109 \\
\hline 2015 & 36.000 .000 & 72.961 .502 .787 \\
\hline 2016 & 54.000 .000 & 65.209 .469 .977 \\
\hline 2017 (Smt I) & 54.000 .000 & 20.751 .170 .875 \\
\hline
\end{tabular}

Sumber: Kantor Pelayanan Pajak Pratama Argamakmur

Dari tabel diatas dapat dilihat bahwa Penghasilan Tidak Kena Pajak mengalami peningkatan, dilihat dari tahun 2014 Penghasilan Tidak Kena Pajak sebesar 24.300.000,- pada tahun 2015 Penghasilan Tidak Kena Pajak meningkat sesuai dengan Peraturan Menteri Keuangan RI Nomor 122/pmk.010/tahun 2015 sebesar 36.000.000,- pada tahun 2016 Penghasilan Tidak Kena Pajak meningkat sesuai dengan Peraturan Menteri Keuangan RI Nomor 101/pmk.010/tahun 2016 sebesar 54.000.000,-.Dilihat dari peningkatan jumlah Penghasilan Tidak Kena Pajak setiap tahunnya tidak sama halnya dengan Penerimaan Pajak Penghasilan Orang 
Pribadi yang mengalami kenaikan dan penurunan mulai dari tahun 2014 (Smt II) Penerimaan Pajak Penghasilan Orang Pribadi mengalami peningkatan sebesar Rp 45.557.188.109,- pada tahun 2015 Penerimaan Pajak Penghasilan Orang Pribadi mengalami penurunan sebesar Rp 72.961.502.787,-- pada tahun 2016 Penerimaan Pajak Penghasilan Orang Pribadi mengalami penurunan sebesar $\mathrm{Rp}$ 65.209.469.977,- pada tahun 2017 (Smt I) Penerimaan Pajak Penghasilan Orang Pribadi mengalami penurunan sebesar Rp 20.751.170.875,-.

\section{Hasil Analisis Regresi Sederhana}

Hasil Output SPSS Koefesien Regresi Linear Sederhana

Coefficients $^{a}$

\begin{tabular}{|c|r|r|r|r|r|}
\hline \multirow{2}{*}{ Model } & \multicolumn{2}{|c|}{ Unstandardized Coefficients } & \multicolumn{1}{c|}{$\begin{array}{c}\text { Standardized } \\
\text { Coefficients }\end{array}$} & & \\
\cline { 2 - 6 } & $\mathrm{B}$ & Std. Error & Beta & $\mathrm{t}$ & Sig. \\
\hline $1 \quad$ (Constant) & 9461924484.969 & 1948698545.997 & & 4.856 & 0.000 \\
$\begin{array}{l}\text { Penghasilan } \\
\text { Tidak Kena } \\
\text { Pajak }\end{array}$ & -1054.200 & 524.412 & -0.326 & -2.010 & 0.052 \\
\hline
\end{tabular}

a. Dependent Variable: Penerimaan Pajak Penghasilan Orang Pribadi

Berdasarkan hasil analisis data pada tabel di atas dapat diketahui persamaan regresi sebagai berikut:

$$
\begin{array}{ll}
\mathrm{Y} & =\mathrm{a}+\mathrm{bX}, \text { dimana nilai } \\
\mathrm{a} & =9461924484.969 \\
\mathrm{~b} & =-1054.200 \\
\mathrm{Y} & =9461924484.969-1054.200 \mathrm{X}
\end{array}
$$

Nilai konstanta (a) adalah 9461924484.969, artinya jika PTKP (X) nilainya 0, maka akan mempengaruhi penerimaan pajak penghasilan orang pribadi (Y) sebesar 9461924484.969. Koefesien regresi (b) sebesar -1054.200, artinya jika PTKP (X) mengalami perubahan 1 satuan. Maka akan mempengaruhi penerimaan pajak penghasilan orang pribadi (Y) sebesar -1054.200. sehingga dapat dilihat apabila nilai (X) mengalami perubahan sebesar 1 satuan maka nilai (Y) sama dengan 9461923430.77.

Koefesien Determinasi Penghasilan Tidak Kena Pajak dan Penerimaan Pajak Penghasilan Orang Pribadi

\begin{tabular}{|l|r|r|r|c|}
\hline \multicolumn{1}{|c|}{ Model Summary } \\
\hline Model & $\mathrm{R}$ & R Square & \multicolumn{1}{c|}{$\begin{array}{c}\text { Adjusted R } \\
\text { Square }\end{array}$} & $\begin{array}{c}\text { Std. Error of the } \\
\text { Estimate }\end{array}$ \\
\hline 1 & $0.326^{\mathrm{a}}$ & 0.106 & 0.080 & $3.04783 \mathrm{E9}$ \\
\hline
\end{tabular}


Model Summary

\begin{tabular}{|l|r|r|r|c|}
\hline Model & $\mathrm{R}$ & $\mathrm{R}$ Square & \multicolumn{1}{c|}{$\begin{array}{c}\text { Adjusted R } \\
\text { Square }\end{array}$} & $\begin{array}{c}\text { Std. Error of the } \\
\text { Estimate }\end{array}$ \\
\hline 1 & $0.326^{\mathrm{a}}$ & 0.106 & 0.080 & $3.04783 \mathrm{E} 9$ \\
\hline
\end{tabular}

a. Predictors: (Constant), Penghasilan Tidak Kena Pajak

Berdasarkan hasil output SPSS di atas maka dapat dilihat besarnya hubungan variabel ptkp (X) dengan Penerimaan pajak penghasilan orang pribadi (Y) adalah 0,106. Hal ini menunjukkan hubungan yang sangat lemah karena nilai koefesien determinasi mendekati 0 (nol). Dan besarnya sumbangan variabel Penghasilan Tidak Kena Pajak (X) terhadap Penerimaan Pajak Penghasilan Orang Pribadi (Y) adalah $10,6 \%$ sedangkan sisanya $89,4 \%$ dipengaruhi oleh variabel yang tidak diteliti dalam penelitian ini.

\section{Uji Hipotesis t (Uji t)}

\begin{tabular}{|l|r|r|r|r|r|}
\hline \multirow{2}{*}{ Model } & \multicolumn{2}{|c|}{ Unstandardized Coefficients } & \multicolumn{1}{|c|}{$\begin{array}{c}\text { Standardized } \\
\text { Coefficients }\end{array}$} & & \\
\cline { 2 - 5 } & $\mathrm{B}$ & Std. Error & Beta & $\mathrm{t}$ & Sig. \\
\hline $1 \quad \begin{array}{l}\text { (Constant) } \\
\text { Penghasilan } \\
\text { Tidak Kena } \\
\text { Pajak }\end{array}$ & 9461924484.969 & 1948698545.997 & & 4.856 & 0.000 \\
& -1054.200 & 524.412 & -0.326 & -2.010 & 0.052 \\
\hline
\end{tabular}

a. Dependent Variable: Penerimaan Pajak Penghasilan Orang Pribadi

Dari hasil pengolahan data dapat diperoleh $t_{\text {hitung }}-2.010$ dan $t_{\text {tabel }}$ sebesar 1.305. Apabila kedua nilai tersebut dibandingkan, maka nilai $\mathrm{t}_{\text {hitung }}-2.010 \leq \mathrm{t}_{\text {tabel }} 1.305$, terlihat pula bahwa nilai Sig $0,052 \leq \alpha 0,1$ maka $\mathrm{H}_{1}$ ditolak dan $\mathrm{H}_{0}$ diterima. Nilai t negatif menunjukkan bahwa Penghasilan Tidak Kena Pajak (X) mempunyai hubungan yang tidak searah dengan Penerimaan Pajak Penghasilan Orang Pribadi (Y). Ini berarti bahwa Penghasilan Tidak Kena Pajak berpengaruh negatif dan signifikan terhadap Penerimaan Pajak Penghasilan Orang Pribadi.

\section{PEMBAHASAN}

Dalam penelitian telah dilakukan tiga pengujian yaitu uji analisis regresi Linear Sederhana, koefesien determinasi, dan uji t, yang mana pengujian ini bertujuan untuk mengetahui pengaruh Perubahan Penghasilan Tidak Kena Pajak Terhadap Penerimaan Pajak Penghasilan Orang Pribadi Pada Kantor Pelayanan Pajak Pratama Argamakmur. Berdasarkan hasil analisis data diketahui persamaan regresi 9461924484.969 - 1054.200 (X), ini berarti disetiap penambahan sebesar 1 (satu) pada variable X akan mempengaruhi vatiabel Y sebesar -1054.200. dapat disimpulkan bahwa apabila jumlah Penghasilan Tidak Kena Pajak mengalami peningkatan maka Penerimaan Pajak Penghasilan Orang Pribadi akan penurunan. 
Demikian sebaliknya jika Penghasilan Tidak Kena Pajak mengalami penurunan maka Penerimaan pajak Penghasilan Orang Pribadi akan meningkat. Berdasarkan hasil Output SPSS Koefesien Determinasi diketahui bahwa terdapat hubungan yang sangat lemah antara penghasilan tidak kena pajak (X) dengan Penerimaan pajak Penghasilan Orang pribadi (Y). hal ini terbukti bahwa nilai koefesien determinasi adalah 0.106 mendekati 0. Ini berarti bahwa Penghasilan Tidak Kena Pajak berpengaruh negatif dan signifikan terhadap Penerimaan Pajak Penghasilan Orang Pribadi pada Kantor Pelayanan Pajak Pratama Argamakmur ini dibuktikan dalam uji hipotesis, yang mana dalam pengujiannya menggunakan uji t. dari hasil pengolahan data, bahwa nilai $t_{\text {hitung }}(-2.010) \leq t_{\text {tabel }}(1.305)$ yang berarti bahwa Penghasilan Tidak Kena Pajak secara signifikan berpengaruh negatif terhadap Penerimaan Pajak Penghasilan Orang Pribadi pada Kantor Pelayanan Pajak Pratama Argamakmur.

\section{KESIMPULAN DAN SARAN \\ Kesimpulan}

Berdasarkan hasil analisis yang telah dilakukan mengenai pengaruh Penghasilan Tidak Kena Pajak terhadap Penerimaan Pajak Penghasilan Orang Pribadi pada Kantor Pelayanan Pajak Pratama Argamakmur, maka dapat diperoleh kesimpulan bahwa:

1. Tarif Penghasilan Tidak Kena Pajak Selalu meningkat sesuai dengan Peraturan Undang-undang dan Peraturan menteri Keuangan, sedangkan Penerimaan Pajak Penghasilan Orang Pribadi Mengalami Penurunan dari tahun 2014 (Smt II)-2017 (Smt I) yaitu tahun 2014 (Smt I) Penerimaan Pajak Penghasilan Orang Pribadi mengalami peningkatan sebesar Rp 45.557.188.109,- pada tahun 2015 Penerimaan Pajak Penghasilan Orang Pribadi mengalami penurunan sebesar Rp 72.961.502.787,- pada tahun 2016 Penerimaan Pajak Penghasilan Orang Pribadi mengalami penurunan sebesar Rp 65.209.469.977,-- pada tahun 2017 (Smt II) Penerimaan Pajak Penghasilan Orang Pribadi mengalami penurunan sebesar Rp 20.751.170.875,-.

2. Pada hasil pengujian regresi linear sederhana data sebesar (Y) = 9461924484.969 - 1054.200 (X), berarti setiap penambahan pada Penghasilan tidak Kena Pajak (X) berpengaruh negatif terhadap Penerimaan Pajak penghasilan Orang Pribadi (Y).

3. Analisis data menggunakan koefesien determinasi adalah sebesar 0.106, ini berarti bahwa Penghasilan Tidak Kena Pajak Memiliki hubungan yang sangat lemah terhadap Penerimaan pajak penghasilan Orang Pribadi. Dan hasil pengujian hipotesis diperoleh nilai $t_{\text {hitung }}$ sebesar -2.010 dan nilai $t_{\text {tabel }} 1.305$. apabila kedua nilai tersebut dibandingkan, maka nilai $\mathrm{t}_{\text {hitung }}-2.010 \leq \mathrm{t}_{\text {tabel }} 1.305$ yang berarti bahwa Penghasilan Tidak Kena Pajak secara signifikan berpengaruh negatif terhadap Penerimaan Pajak Penghasilan Orang Pribadi.

\section{Saran}

Berdasarkan hasil penelitian dan kesimpulan yang diperoleh dari penelitian ini, maka terdapat beberapa saran sebagai berikut: 
1. KPP Pratama Argamakmur meningkatkan sosialisasi mengenai manfaat dari kebijakan-kebijakan yang diberikan pemerintah agar wajib pajak paham mengenai pentingnya membayar pajak dan agar kebijakan-kebijakan ini berjalan sesuai dengan tujuan.

2. Melakukan sosialisasi kepada wajib pajak yang belum mendaftarkan diri sebagai wajib pajak ke KPP Pratama Argamakmur, karena masih banyak Wajib Pajak Yang penghasilan Diatas Penghasilan Tidak Kena Pajak yang belum mendaftarkan diri sebagai wajib pajak.

\section{DAFTAR PUSTAKA}

Darwis, Tommy K. Dampak Kenaikan PTKP dan Strategi DJP. http://www.pajak.go.id/content/article/dampak-kenaikan-ptkp-danstrategidjp. Diakses Pada Tanggal 07 November 2017.

Hutagaol, John. 2007. Perpajakan: Isu-isu Kontemporer. Graha Ilmu. Yogjakarta.

Hasan, M. Iqbal. 2012. Pokok-pokok Materi Statistik II (Statistik Inferensif). PT. Bumi Aksara. Jakarta.

Mardalis. 2009. Metode Penelitian (suatu pendekatan proposal). Edisi 11. PT. Bumi Aksara. Jakarta.

Mardiasmo. 2011. Perpajakan Edisi Revisi 2011. Penerbit andi. Yogyakarta.

Muljono, Djoko. 2009. Pengantar PPh dan PPh 21 Lengkap dengan undangundang. penerbit Andi. Yogyakarta.

Nuritomo. 2007. Pengaruh Peningkatan Penghasilan Tidak Kena Pajak Terhadap Penerimaan Pajak pada KPP Yokyakarta Satu. Jurnal Fakultas Ekonomi. Yogyakarta: Universitas Atma Jaya.

http://e-journal.uajy.ac.id/7780/1/EA014175.pdf

Peraturan Menteri Keuangan RI Nomor 162/pmk.011/tahun 2012 Tentang Penyesuaian Besarnya Penghasilan Tidak Kena Pajak. Diakses dari www.online-pajak.com pada tanggal 06 februari 2018.

Peraturan Menteri Keuangan RI Nomor 122/pmk.010/tahun 2015 Tentang Penyesuaian Besarnya Penghasilan Tidak Kena Pajak. Diakses dari www.online-pajak.com pada tanggal 06 februari 2018.

Peraturan Menteri Keuangan RI Nomor 101/pmk.010/tahun 2016 Tentang Penyesuaian Besarnya Penghasilan Tidak Kena Pajak. Diakses dari www.online-pajak.com pada tanggal 06 februari 2018. 
Pramesty, Getut. 2017. Statistika Penelitian dengan SPSS 24. PT Elex Media Komputindo. Jakarta.

Priantara, Diaz. 2016. Perpajakan Indonesia. Edisi 3. Mitra Wacana Media. Jakarta.

Resmi,Siti. 2013. Perpajakan Teori dan Kasus. Salemba Empat. Jakarta.

Salim, Michel dan Lili Syafitri. 2013. Analisis Pengaruh kenaikan PTKP terhadap penerimaan Pajak Penghasilan Pada Kantor Pelayanan Pajak Pratama Palembang Ilir Barat. Jurnal Akuntansi. Palembang: STIE MDP. http://eprints.mdp.ac.id/711/1/Jurnal\%202009210057\%20Michel\%20Salim.pdf

Simanjuntak, Timbul Hamongang dan Imam Muklis. 2012. Dimensi Ekonomi Perpajakan dalam Pembangunan Ekonomi. Raih Asa Sukses. Bogor.

Sugiyono. 2012. Metode Penelitian Kuantitatif Kualitatif dan $R \& D$. Alfabeta. Bandung.

. 2013. Metode Penelitian Bisnis (Pendekatan Kualitatif, Kuantitatif, dan $R \& D)$. Bandung : Alfabeta

Sumarsan, Thomas. 2012. Perpajakan Indonesia .Edisi 3. Empat Dua Media. Malang.

Undang-Undang Nomor 13 Tahun 1985 tentang Bea Materai. diakses dari www.pajak.go.id pada tanggal 14 November 2017

Undang-Undang Nomor 28 tahun 2007 tentang Ketentuan Umum dan Tata Cara Perpajakan.Diakses dari www.pajak.go.id pada tanggal 10 November 2017

Undang-Undang Nomor 36 Tahun 2008 Tentang Pajak Penghasilan. Diakses dari www.pajak.go.id pada tanggal 11 November 2017

Undang - Undang Nomor 42 Tahun 2009 Tentang Pajak Pertambahan Nilai Barang dan Jasa dan Pajak Penjualan Atas Barang Mewah. www.pajak.go.id pada tanggal 14 November 2017

Waluyo, 2013. Perpajakan Indonesia, Salemba Empat, Jakarta. 